\title{
Measurement of peroxiredoxin- 4 serum levels in rat tissue and its use as a potential marker for hepatic disease
}

\author{
RITSU ITO ${ }^{1}$, MOTOKO TAKAHASHI ${ }^{2}$, HIDEYUKI IHARA ${ }^{1}$, HIROKI TSUKAMOTO ${ }^{1}$, \\ JUNICHI FUJII $^{3}$ and YOSHITAKA IKEDA ${ }^{1}$
}

\begin{abstract}
${ }^{1}$ Division of Molecular Cell Biology, Department of Biomolecular Sciences, Faculty of Medicine, Saga University, Saga 849-8501; ${ }^{2}$ Department of Biochemistry, Sapporo Medical University School of Medicine,

Chuo-Ku, Sapporo 060-8556; ${ }^{3}$ Department of Biochemistry and Molecular Biology,

Graduate School of Medical Science, Yamagata University, Yamagata 990-9585, Japan
\end{abstract}

Received January 23, 2012; Accepted April 24, 2012

DOI: $10.3892 / \mathrm{mmr} .2012 .935$

\begin{abstract}
Peroxiredoxin (Prx)-4, a secretable endoplasmic reticulum (ER)-resident isoform of the mammalian Prx family, functions as a thioredoxin-dependent peroxidase. It is acknowledged that Prx-4 plays a role in the detoxification of hydrogen peroxide, and potentially other peroxides, which may be generated during the oxidative folding of proteins and oxidative stress in the ER. The present study was undertaken in order to specifically quantify the tissue levels of Prx-4. To accomplish this, an enzyme-linked immunosorbent assay was developed using a specific polyclonal antibody produced by immunizing a rabbit with native recombinant rat $\operatorname{Prx}-4$ protein. The assay was used to detect Prx- 4 in the range of 0.1 and $10 \mathrm{ng} / \mathrm{ml}$, and to investigate tissue distribution in rats. Using this immunoassay, we found that the serum levels of Prx-4 were substantially lower in asymptomatic Long-Evans Cinnamon rats, a rat model of Wilson's disease, compared to normal rats. In addition, the treatment of rat hepatoma cells with $\mathrm{N}$-acetylcysteine led to a significant increase in the release of $\mathrm{Prx}-4$ protein into the medium; thus, it appears likely that the secretion of Prx-4 is associated with the redox state within cells. These results suggest that serum Prx-4 has potential for use as a biomarker for hepatic oxidative stress.
\end{abstract}

\section{Introduction}

Since many organisms that live under aerobic conditions are exposed to reactive oxygen species (ROS), they have developed a protective or defensive system against oxidative stress, which includes the production of a variety of antioxidant enzymes, including superoxide dismutases, catalase and glutathione

Correspondence to: Dr Yoshitaka Ikeda, Division of Molecular Cell Biology, Department of Biomolecular Sciences, Faculty of Medicine, Saga University, 5-1-1 Nabeshima, Saga 849-8501, Japan E-mail: yikeda@med.saga-u.ac.jp

Key words: peroxiredoxin, oxidative stress, Long-Evans Cinnamon rat, enzyme-linked immunosorbent assay, liver peroxidases (1-3). These enzymes are important in detoxifying ROS, some of which are generated during cellular respiration. In addition to these enzymes, a distinct class of antioxidant proteins has been identified and is referred to as peroxiredoxins (Prxs) (4-6).

Prx is a family of proteins that act on peroxides in a thioredoxin-dependent manner (4). In mammals, this protein family consists of six members, Prx-1 to $-6(4,7)$. Their common feature is the presence of two redox-sensitive cysteine residues in the active site, thus referred to as a 2-Cys type, with the exception of Prx-6, which has a single catalytic cysteine and is thus referred to as a 1-Cys type. During the reduction of peroxides by the 2-Cys-type Prx, the sulfhydryl groups of these two cysteines are oxidized to a disulfide linkage, which are then reduced by thioredoxin (4). Prxs-1-4 are highly homologous in terms of protein structure involving the two active site cysteine residues, while Prx-5 is classified as an atypical 2-Cys Prx due to its low homology $(4,7)$. It is well-known that oxidative stress is closely associated with a number of pathological processes, and thus, the role of the Prx family has been investigated in numerous diseases (8-12). The expression of certain members of the Prx family are altered in a number of human malignancies (13-18). In addition to their role in the detoxification of peroxides, it is also considered that this family is involved in intracellular signal transduction involving $\mathrm{H}_{2} \mathrm{O}_{2}(4,6,19,20)$.

Among the Prx family members, Prx-4 uniquely contains an N-terminal signal peptide (21). The expression of this protein is relatively high in the testis, pancreas and liver, as demonstrated by immunoblotting data. While the majority of the Prx family members are present within cells, for example, in the cytosol for Prx-1 and Prx-2 and in the mitochondria for Prx-3, Prx-4 appears to reside in the endoplasmic reticulum (ER) and is secretable due to the presence of a cleavable signal peptide $(21,22)$. Therefore, Prx- 4 has the potential to be present in extracellular fluids, such as serum. Thus, the quantification of Prx-4 may also be useful for the clinical examination of pathological conditions using serum samples. Although an attempt to examine the serum levels of Prx-4 has recently been reported for sepsis in humans, a complete quantification was not accomplished due to the unavailability of a standard sample and the use of an arbitrary unit which was unique to this 
earlier study (23). In addition, it has not yet been fully clarified in which pathological conditions or in which types of disease this protein is implicated, although available evidence suggests that Prx-4 plays a role in ER stress and the oxidative folding of proteins in the ER $(24,25)$. To extend the clinical usefulness of Prx-4, a more quantitative assay is required to determine and compare Prx-4 levels in various mammalian tissues.

In this study, we report on the preparation of a specific polyclonal antibody by immunization of a rabbit with a purified recombinant Prx-4, which was previously described (26). An enzyme-linked immunosorbent assay (ELISA) was then developed to quantitatively determine its levels in tissues and to investigate alterations of its levels in association with certain pathological conditions using animal models. The findings suggest that the serum level of Prx-4 is associated with the pathological state of the liver and may be of potential value for monitoring oxidative stress in the liver.

\section{Materials and methods}

Cell culture. The rat cell lines used in this study were maintained at $37^{\circ} \mathrm{C}$ in RPMI-1640 (AH66 cells), Eagle's MEM (WB-F344 and RLN-10 cells) and DMEM (RLC-16 cells), all of which were supplemented with 5 or $10 \%$ fetal bovine serum, streptomycin and penicillin, under an atmosphere of $5 \% \mathrm{CO}_{2}$ in humidified air.

Animals. Male Wistar rats were purchased from Japan SLC Inc. (Hamamatsu, Japan) at the age of 6 weeks, and Long-Evans Cinnamon (LEC) rats and Sprague-Dawley (SD) rats were obtained at the age of 18 weeks from Charles River Japan, Inc. (Yokohama, Japan). The rats were maintained under specific pathogen-free conditions at a constant temperature of $20-22^{\circ} \mathrm{C}$ with a 12-h light/dark cycle. The Wister rats were injected with a single dose of $50 \mathrm{mg} / \mathrm{kg}$ streptozotocin (Sigma) to induce diabetes. In the LEC rats, serum alanine transaminase (ALT) and aspartate transaminase (AST) activities were determined using a transaminase assay kit (Wako Pure Chemicals) to verify the occurrence of hepatitis. Animal handling and care were conducted under the protocol approved by the Institutional Animal Research Committee of Saga University.

Expression and purification of recombinant rat Prx-4. Preparation of the recombinant Prx-4 protein was conducted as previously described (26). The recombinant protein was obtained from the extract of the Sf21 cells that had been infected with a recombinant baculovirus encoding a signal peptide-truncated form of rat Prx-4. The enzyme was purified by two successive cation exchanges and gel filtration column chromatographies, following polyethyleneimine precipitation. As previously described (26), the recombinant protein was enzymatically active and homogeneous.

Preparation and biotinylation of rabbit anti-Prx-4 IgG. A total of $500 \mu \mathrm{g}$ of the purified rat PrX-4 was emulsified in Freund's complete adjuvant and injected intracutaneously into the dorsal skin of a female rabbit. Another $500 \mu \mathrm{g}$ of protein in incomplete adjuvant were subcutaneously injected dorsally at two-week intervals. Antiserum was obtained three weeks after the final booster injection. The IgG fraction was prepared from the antiserum by ammonium sulfate precipitation and subsequent column chromatography using Protein A Sepharose Fast Flow (GE Healthcare). Biotinylation of the antibody was conducted using N-hydroxysuccinimide-biotin (Pierce), according to the manufacturer's instructions.

Electrophoresis and immunoblot analysis. After the protein samples were separated using sodium dodecyl sulfate-polyacrylamide gel electrophoresis (SDS-PAGE), they were electrophoretically transferred onto a polyvinylidene fluoride membrane (Millipore). The membrane was blocked by treatment with $1 \%$ skimmed milk in phosphate-buffered saline (PBS) and reacted with the polyclonal rabbit antibody. After washing, the membrane was incubated with a horseradish peroxidase-conjugated antibody against rabbit IgG. Following washing, the reactive protein bands were visualized using an ECL Advance Western Blotting Detection kit (Amersham).

ELISA. The 96-well microtiter plates (Maxisorp, Nunc) were pre-coated with rabbit polyclonal IgG against rat Prx-4. The

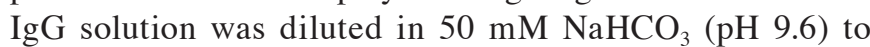
$50 \mu \mathrm{g} / \mathrm{ml}$ and added to the wells. The plates were incubated overnight at $4^{\circ} \mathrm{C}$ and were then blocked by $1 \%$ bovine serum albumin (BSA) after washing with PBS. A total of $50 \mu 1$ of the appropriately diluted samples were added in duplicate to the wells of the plates, followed by incubation at room temperature for $2 \mathrm{~h}$. Biotinylated anti-rat Prx-4 rabbit IgG was added to the plates, and the plates were then allowed to react at room temperature for $1 \mathrm{~h}$. The plates were then incubated at room temperature for $30 \mathrm{~min}$ after adding horseradish peroxidase-conjugated streptavidin to the wells. The plates were washed five times with PBS-Tween-20 (PBS-T) after each step. Detection was performed using a solution of $1 \mathrm{mg} / \mathrm{ml} o$-phenylenediamine as the substrate with $0.015 \%$ $\mathrm{H}_{2} \mathrm{O}_{2}$ in $0.1 \mathrm{M}$ citrate-phosphate buffer ( $\mathrm{pH}$ 5.4). The absorbance at $490 \mathrm{~nm}$ was measured using a microtiter plate reader (Bio-Rad).

Tissue sample preparation for immunoblot analysis and ELISA. The rats were sacrificed after appropriate periods of time, and then the tissues were obtained and stored at $-80^{\circ} \mathrm{C}$ until use. The tissues were homogenized with a Dounce homogenizer in a lysis buffer of $20 \mathrm{mM}$ Tris- $\mathrm{HCl}, 150 \mathrm{mM}$ $\mathrm{NaCl}, 5$ mM EDTA, $1 \%$ (v/v) Nonidet P-40, 10\% (v/v) glycerol, $1 \mathrm{mM}$ phenylmethylsulfonyl fluoride, $2 \mu \mathrm{g} / \mathrm{ml}$ aprotinin and $5 \mu \mathrm{g} / \mathrm{ml}$ leupeptin ( $\mathrm{pH} 7.4$ )

Protein determination. Protein contents were determined using a Bradford protein assay kit (Pierce). BSA was used as the standard.

Statistical analysis. Data were analyzed using the t-test and the results are expressed as the means \pm standard deviation (SD). $\mathrm{P}<0.05$ was considered to indicate a statistically significant difference, unless otherwise stated.

\section{Results}

Antibody raised against native Prx-4 protein. In earlier studies, specific antibodies have been prepared using an 
inactive denatured polypeptide or a synthetic polypeptide as the antigen $(21,23,27)$. The use of the native form of a protein can occassionally prove more benificial for immunization. For example, when an antibody that effectively recognizes a native protein is desired, the latter is recommended. Thus, the enzymatically active recombinant Prx- 4 was purified and used as the antigen to immunize rabbits in this study. The anti-Prx-4 $\mathrm{IgG}$ was purified from antiserum obtained from the immunized rabbits. The specificity of the antibody was verified using immunoblot analysis of several rat tissues (Fig. 1). All samples examined displayed identical protein bands corresponding to a signal peptide-processed form, with the exception of the testis; consistent with a previous study using a different antibody which was raised against a bacterially produced antigen $(21,27)$. No other bands that could correspond to other Prx isoforms with different molecular masses were detected, thus indicating that the specificity of this antibody was sufficient. The results were in accordance with data reported in a previous study, and demonstrated that the protein levels of Prx-4 were relatively higher in the testis, pancreas and liver.

ELISA for Prx-4 and examination of tissue distribution. Although in a previous study, we examined tissue distribution of Prx-4 in rats, the protein levels were roughly estimated by immunoblot analysis (21). In order to more quantitatively estimate the levels of Prx-4 in tissues, we developed an ELISA using the aforementioned antibody. This ELISA involved the immobilized antibody, the biotin-labeled antibody and HRP-conjugated streptavidin, as described in detail in the Materials and methods section. A typical calibration curve for the standard samples is shown in Fig. 2A. As indicated, this assay enabled us to optimally estimate the levels in the range between 0.1 and $10 \mathrm{ng} / \mathrm{ml}$. The re-assessment of the tissue distribution using ELISA was essentially consistent with the results obtained by the immunoblot analyses, as described above, as well as in the previous study. As shown for normal control rats in Fig. 2B, the expression of Prx-4 was significantly higher in the pancreas, liver and testis. The higher expression of Prx-4 in the pancreas and liver may be associated with the possible role of this protein in the oxidative folding of secretory proteins in the ER.

Prx-4 levels in the tissues of streptozotocin-induced diabetic rats. The issue of whether or not Prx- 4 is implicated in diseases of the pancreas and liver has not yet been fully investigated; thus we examined the levels of Prx-4 in certain pathological states using animal models. Eight-week-old Wistar rats were treated with streptozotocin to induce severe diabetes. The occurrence of the disease was verified by high blood sugar levels and the production of urinary sugar. Measurements of blood sugar indicated levels of $130 \pm 35$ and $440 \pm 67 \mathrm{mg} / \mathrm{dl}$ for the control rats and streptozotocin-treated rats, respectively $(\mathrm{P}<0.01$, t-test; $\mathrm{n}=3$ for each group). The protein levels of Prx- 4 were determined by ELISA in various tissues of the control and diabetic rats. As shown in Fig. 2B, although a slight decrease in the Prx-4 level was observed in the liver and pancreas, there was no statistically significant difference in all tissues examined. The mean serum level values of the proteins were estimated to be 1.7 and $2.2 \mathrm{ng} / \mathrm{ml}$ in normal and diabetic rats, respectively. However, a statistical analysis indicated no

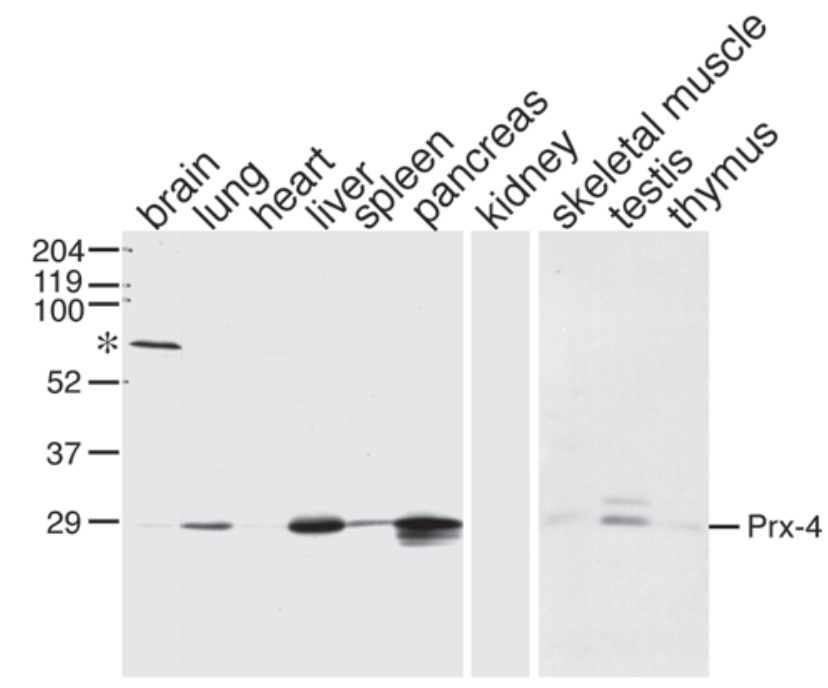

Figure 1. Immunoblot analysis of rat tissues with anti-rat Prx-4 antibody. A total of $50 \mu \mathrm{g}$ of proteins from a tissue homogenate were loaded per lane in SDS-PAGE. Data for skeletal muscle, testis and thymus (right three lanes) are presented by a different gel from that of the other data. *Unidentified protein band reactive for the antibody in the immunoblot, possibly due to being denatured, but not detected in the ELISA. Prx, peroxiredoxin; SDS-PAGE, sodium dodecyl sulfate-polyacrylamide gel electrophoresis; ELISA, enzyme-linked immunosorbent assay.
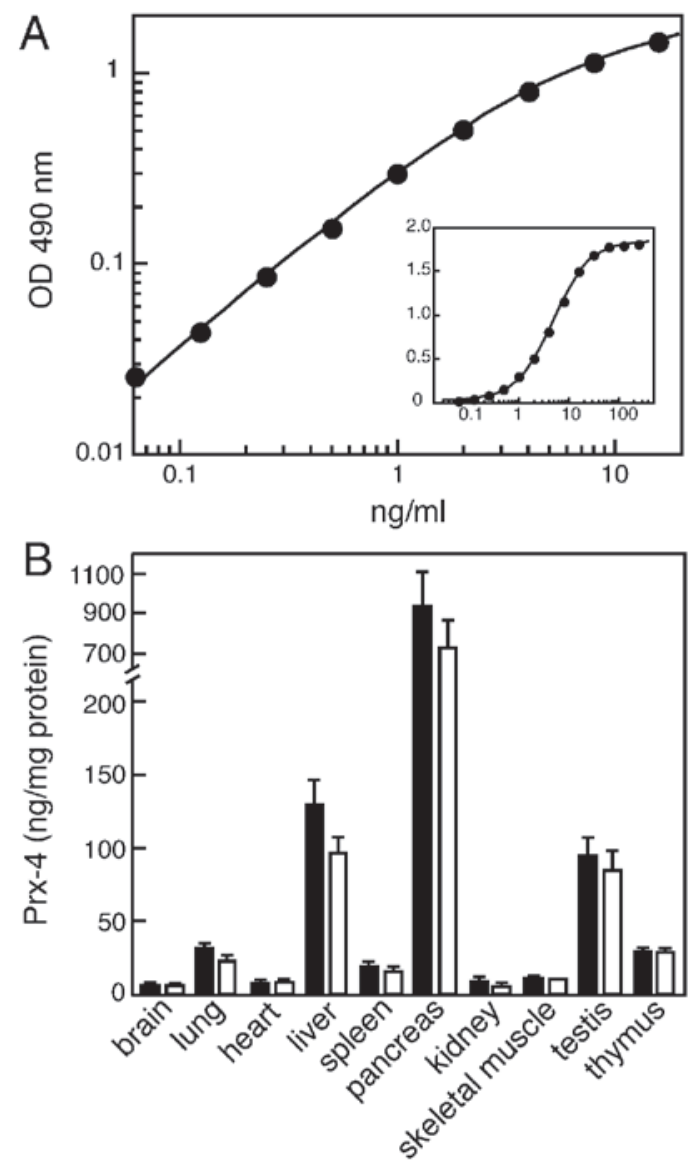

Figure 2. ELISA for rat $\operatorname{Prx}-4$ and tissue distribution in normal and diabetic rats. (A) A linear portion of the standard ELISA curve is shown. Superimposed is the overall standard curve for a wider range. (B) Tissue distribution in normal and streptozotocin-induced diabetic rats. Closed and open columns represent data for normal and diabetic rats, respectively. ELISA, enzyme-linked immunosorbent assay; Prx, peroxiredoxin. 
A

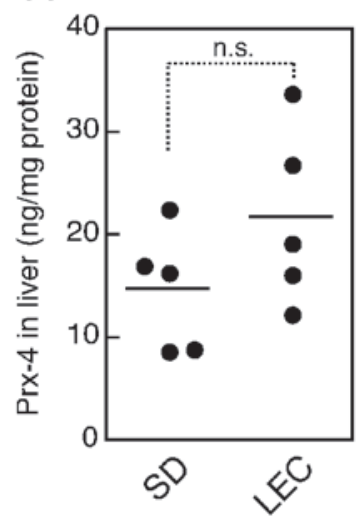

B

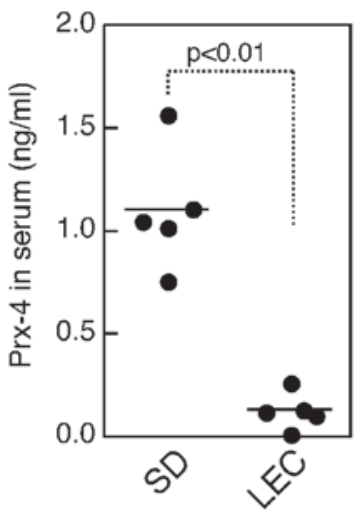

C

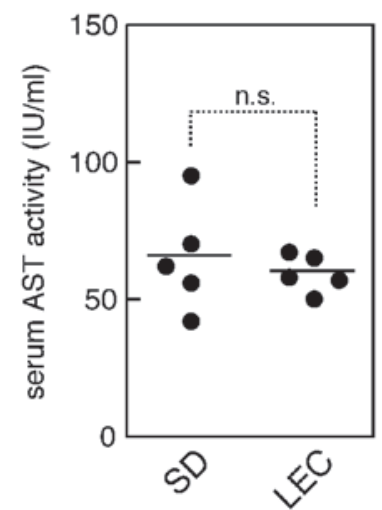

D

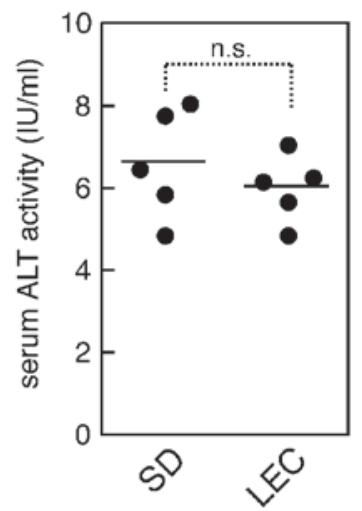

Figure 3. Prx-4 levels and transaminase activities in LEC rats. Levels of Prx-4 in the (A) liver and (B) serum were assayed in LEC rats compared with the control SD rats. Serum transaminase activities of (C) AST and (D) ALT were also determined in the two rat strains. Serum Prx-4 levels are significantly different between LEC and SD rats $(\mathrm{P}<0.01, \mathrm{n}=5$ for each group), but no statistical significance was observed for the liver Prx- 4 or for serum transaminases. Prx, peroxiredoxin; LEC, Long-Evans Cinammon; SD, Sprage-Dawley; AST, aspartate transaminase; ALT, alanine transaminase.
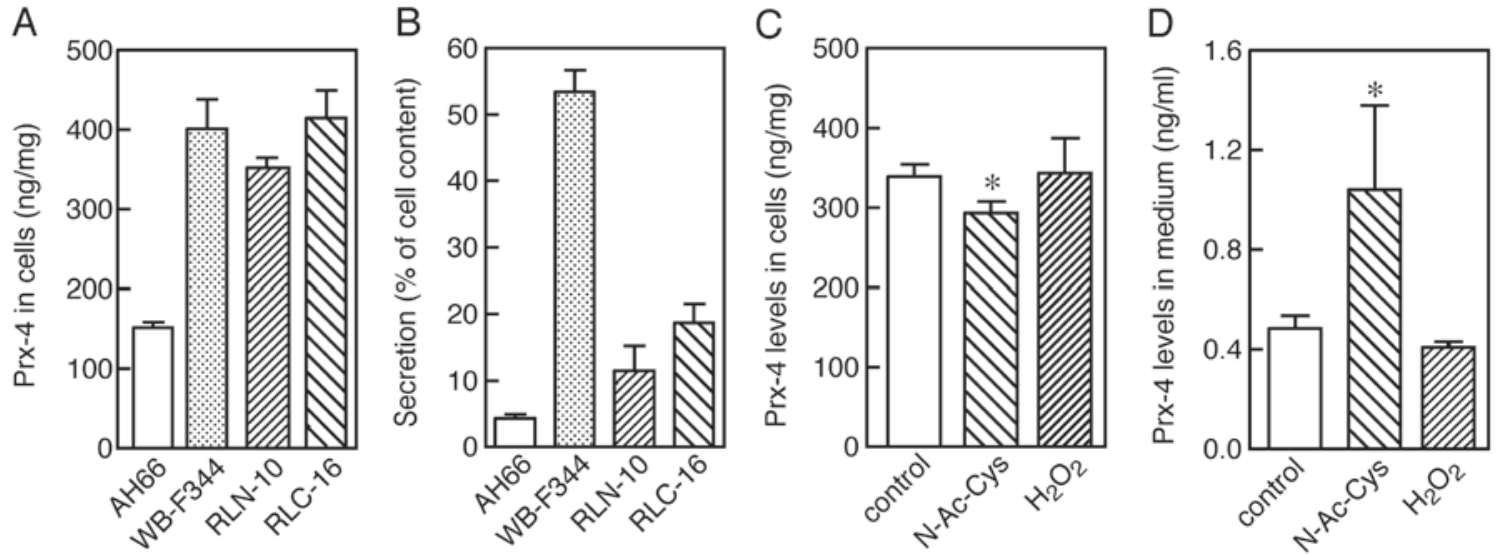

Figure 4. Prx-4 levels in various cell lines derived from rat liver and effects of an oxidant and a reductant on the secretion. (A) Prx-4 contents in cells were determined for various rat cell lines. (B) Secreted Prx-4 was estimated by evaluating the levels in the medium, and the data are expressed as the relative value to the contents in the cells. (C and D) Effects of $0.05 \mathrm{mM} \mathrm{H}_{2} \mathrm{O}_{2}$ and $5 \mathrm{mM}$ N-acetyl cysteine (N-Ac-Cys) on the secretion of Prx-4 were examined in RLN-10 cells. Prx-4 contents in cells and medium were assayed $24 \mathrm{~h}$ after the addition of these agents. *Significant difference compared to controls ( $\mathrm{P}<0.05)$. Prx, perioxiredoxin.

significant difference despite a tendency toward an increase caused by the streptozotocin treatment.

Alteration of Prx-4 levels in hepatic disease model rats. Another animal model, which has been used for liver disease, is the LEC rats (28). LEC rats are frequently used as a Wilson's disease animal model for which a genetic defect was found in the copper transporter ATPase gene, Atp7b $(29,30)$. The rats exhibit abnormal copper accumulation in the liver, and suffer from the development of hepatitis and hepatocarcinogenesis (31). Prx-4 levels were determined in the livers and sera of 24-week-old LEC rats. SD rats of the same age were used as the healthy controls. The LEC rats appeared to be healthy in this study, and did not appear to suffer from hepatitis, as also indicated by ALT and AST assays (Fig. 3C and D). When the serum levels of Prx-4 were determined, however, the data indicated that the levels in the LEC rats were significantly less than those in the normal rats (Fig. 3B). On the other hand, in contrast to the serum levels, LEC rats demonstrated a trend toward a higher level in the liver, compared to the controls, although no statistically significant difference was observed for Prx-4 levels in the liver (Fig. 3A).

Expression of Prx-4 in rat hepatic cell lines and effects of redox stress on secretion from cells. As suggested by the lower levels of serum Prx-4 in LEC rats, it appeared likely that the redox state affects the release of Prx-4 from the cells since it is well-known that an abnormal accumulation of hepatic copper causes oxidative stress in LEC rats $(32,33)$. Rat hepatic cell lines were used in order to assess whether oxidative stress alters the secretion of Prx-4. Four cell lines, AH66, WB-F344, RLN-10 and RLC-16, were cultured for three days, and the PrX-4 levels in the cells and medium were then separately determined by ELISA. The expression of Prx-4 was observed in all cell lines examined (Fig. 4A). However, the levels of the Prx-4 protein varied in the medium, regardless of the contents associated with the cells, suggesting that the efficiency of secretion varies among the cell lines (Fig. 4B). Only a single 
protein band, in which the signal peptide was cleaved off, was observed for all cell lines in the immunoblot analyses (data not shown), suggesting that variations in the extent of secretion are not due to differences in the processing capability of the cells. The difference in secretion appeared to be due to the status or character of the cells rather than to a factor intrinsic to the protein. As observed in RLN-10 cells, treatment with $5 \mathrm{mM}$ $\mathrm{N}$-acetylcysteine for $24 \mathrm{~h}$ significantly increased the extent of secretion into the medium, accompanied by a corresponding decrease in the cells. However, the presence of $0.05 \mathrm{mM} \mathrm{H}_{2} \mathrm{O}_{2}$ did not greatly suppress the secretion of Prx-4 $24 \mathrm{~h}$ after addition. This discrepancy between the experiments using the reducing and the oxidizing agent may be explained by more intensive oxidative stress in the cells cultured under the condition of $20 \% \mathrm{O}_{2}$ than in the tissues where a partial pressure of $\mathrm{O}_{2}$ is expected to be lower (34-36). These results suggest that the release of Prx- 4 from cells is, at least in part, affected by the redox state of the cells.

\section{Discussion}

In this study, we prepared a polyclonal antibody against rat Prx-4 using a purified recombinant protein as the antigen, and subsequently developed an immunoassay for quantitatively determining the levels of the Prx-4 protein. An enzymatic activity assay for thioredoxin-dependent peroxidase cannot be used to specifically evaluate the tissue levels of Prx-4 as the peroxidase activities of the mammalian Prx family are relatively weak; much less than other typical peroxidases, such as glutathione peroxidase. In addition, the enzymatic activity assay does not permit the measurement of each individual member of the Prx family. Therefore, an isoform-specific immunoassay would be useful and desirable for such a quantification in investigations of the role of Prx-4 in various diseases.

The development of the ELISA for Prx-4 confirmed high levels of expression in the pancreas, liver and testis of rats. Considering tissue mass, the total content of $\operatorname{Prx}-4$ is highest in the liver, and thus it is more likely that the supply of the protein to the blood largely depends on the liver. As previously described, Prx-4 appears to be highly expressed in exocrine pancreas rather than islets (37), and another study also reported that another Prx isoform is highly expressed in pancreatic islet cells (38). Consistent with these findings, it would be reasonable that no significant alteration of Prx-4 levels in the serum would be observed in the experiments using streptozotocininduced diabetic rats.

LEC rats were initially identified as a mutant rat with spontaneous hepatitis and hepatoma, and thereafter were considered as a Wilson's disease model. In the liver, Prx-4 levels were slightly higher in the LEC rats compared with the control SD rats; however, no statistically significant difference was found, while this trend was inverse to the levels of serum Prx-4. Thus, it appears that the release of Prx-4 from the liver is suppressed in LEC rats. When the LEC rats were used in experiments, they did not display any symptoms of hepatitis, i.e., no apparent jaundice and no increase in serum transaminase activities (Fig. 3C and D), indicating that the lower levels of serum Prx-4 were not directly associated with inflammation. As suggested by in vitro studies using cultured cells, however, it appears more likely that the secretion of Prx-4 from the cells can be regulated or affected by the redox state. Therefore, even very mild oxidative stress, which is so weak that it does not cause hepatitis, might potentially affect the secretion of Prx- 4 into the blood.

The findings from this study suggest that the serum levels of Prx-4 are associated with the redox state of the liver, and therefore it is possible that this protein may be utilized as a biomarker for oxidative stress in the liver. The application of the anti-rat Prx-4 polyclonal antibody to human cell lines demonstrated no apparent reactivity (data not shown). The clinical utility of diagnosing human liver diseases will await optimizing the ELISA procedures for use in conjunction with human samples.

\section{References}

1. Halliwell B and Gutteridge JMC: Free Radicals in Biology and Medicine. 4th edition. Oxford University Press, Oxford, United Kingdom, 2007.

2. Fridovich I: Oxygen toxicity: a radical explanation. J Exp Biol 201: 1203-1209, 1998.

3. Papa S and Skulachev VP: Reactive oxygen species, mitochondria, apoptosis and aging. Mol Cell Biochem 174: 305-319, 1997.

4. Rhee SG, Kang SW, Chang TS, Jeong W and Kim K: Peroxiredoxin, a novel family of peroxidases. IUBMB Life 52: 35-41, 2001.

5. Rhee SG, Yang KS, Kang SW, Woo HA and Chang TS: Controlled elimination of intracellular $\mathrm{H}_{2} \mathrm{O}_{2}$ : regulation of peroxiredoxin, catalase, and glutathione peroxidase via post-translational modification. Antioxid Redox Signal 7: 619-626, 2005.

6. Rhee SG, Chae HZ and Kim K: Peroxiredoxins: a historical overview and speculative preview of novel mechanisms and emerging concepts in cell signaling. Free Radic Biol Med 38: $1543-5152,2005$.

7. Fujii J and Ikeda Y: Advances in our understanding of peroxiredoxin, a multifunctional, mammalian redox protein. Redox Rep 7: 123-130, 2002.

8. Chang XZ, Li DQ, Hou YF, Wu J, Lu JS, Di GH, Jin W, Ou ZL, Shen ZZ and Shao ZM: Identification of the functional role of peroxiredoxin 6 in the progression of breast cancer. Breast Cancer Res 9: R76, 2007.

9. Iraqui I, Faye G, Ragu S, Masurel-Heneman A, Kolodner RD and Huang ME: Human peroxiredoxin PrxI is an orthologue of yeast Tsa1, capable of suppressing genome instability in Saccharomyces cerevisiae. Cancer Res 68: 1055-1063, 2008.

10. Song IS, Kim SU, Oh NS, Kim J, Yu DY, Huang SM, Kim JM, Lee DS and Kim NS: Peroxiredoxin I contributes to TRAIL resistance through suppression of redox-sensitive caspase activation in human hepatoma cells. Carcinogenesis 30: 1106-1114, 2009.

11. Neumann CA, Krause DS, Carman CV, Das S, Dubey DP, Abraham JL, Bronson RT, Fujiwara Y, Orkin SH and Van Etten RA: Essential role for the peroxiredoxin Prdx1 in erythrocyte antioxidant defence and tumour suppression. Nature 424: 561-565, 2003.

12. Fang J, Nakamura T, Cho DH, Gu Z and Lipton SA: S-nitrosylation of peroxiredoxin 2 promotes oxidative stress-induced neuronal cell death in Parkinson's disease. Proc Natl Acad Sci USA 104: 18742-18747, 2007.

13. Cha MK, Suh KH and Kim IH: Overexpression of peroxiredoxin I and thioredoxin1 in human breast carcinoma. J Exp Clin Cancer Res 28: 93, 2009.

14. Karihtala P, Mantyniemi A, Kang SW, Kinnula VL and Soini Y: Peroxiredoxins in breast carcinoma. Clin Cancer Res 9: 3418-3424, 2003

15. Quan C, Cha EJ, Lee HL, Han KH, Lee KM and Kim WJ: Enhanced expression of peroxiredoxin I and VI correlates with development, recurrence and progression of human bladder cancer. J Urol 175: 1512-1516, 2006.

16. Lehtonen ST, Svensk AM, Soini Y, Paakko P, Hirvikoski P, Kang SW, Saily M and Kinnula VL: Peroxiredoxins, a novel protein family in lung cancer. Int J Cancer 111: 514-521, 2004.

17. Yanagawa T, Iwasa S, Ishii T, Tabuchi K, Yusa H, Onizawa K, Omura K, Harada H, Suzuki H and Yoshida H: Peroxiredoxin I expression in oral cancer: a potential new tumor marker. Cancer Lett 156: 27-35, 2000. 
18. Chang JW, Jeon HB, Lee JH, Yoo JS, Chun JS, Kim JH and Yoo YJ: Augmented expression of peroxiredoxin I in lung cancer. Biochem Biophys Res Commun 289: 507-512, 2001.

19. Rhee SG, Kang SW, Jeong W, Chang TS, Yang KS and Woo HA Intracellular messenger function of hydrogen peroxide and its regulation by peroxiredoxins. Curr Opin Cell Biol 17: 183-189, 2005.

20. Rhee SG: Cell signaling. $\mathrm{H}_{2} \mathrm{O}_{2}$, a necessary evil for cell signaling. Science 312: 1882-1883, 2006.

21. Okado-Matsumoto A, Matsumoto A, Fujii J and Taniguchi N: Peroxiredoxin IV is a secretable protein with heparin-binding properties under reduced conditions. J Biochem 127: 493-501, 2000.

22. Tavender TJ, Sheppard AM and Bulleid NJ: Peroxiredoxin IV is an endoplasmic reticulum-localized enzyme forming oligomeric complexes in human cells. Biochem J 411: 191-199, 2008.

23. Schulte J, Struck J, Bergmann A and Kohrle J: Immunoluminometric assay for quantification of peroxiredoxin 4 in human serum. Clin Chim Acta 411: 1258-1263, 2010.

24. Tavender TJ and Bulleid NJ: Peroxiredoxin IV protects cells from oxidative stress by removing $\mathrm{H}_{2} \mathrm{O}_{2}$ produced during disulphide formation. J Cell Sci 123: 2672-2679, 2010.

25. Bertolotti M, Yim SH, Garcia-Manteiga JM, Masciarelli S, Kim YJ, Kang MH, Iuchi Y, Fujii J, Vene R, Rubartelli A, Rhee SG and Sitia R: B- to plasma-cell terminal differentiation entails oxidative stress and profound reshaping of the antioxidant responses. Antioxid Redox Signal 13: 1133-1144, 2010.

26. Ikeda Y, Ito R, Ihara H, Okada T and Fujii J: Expression of $\mathrm{N}$-terminally truncated forms of rat peroxiredoxin-4 in insect cells. Protein Expr Purif 72: 1-7, 2010.

27. Matsumoto A, Okado A, Fujii T, Fujii J, Egashira M, Niikawa N and Taniguchi N: Cloning of the peroxiredoxin gene family in rats and characterization of the fourth member. FEBS Lett 443: 246-250, 1999.

28. Yoshida MC, Masuda R, Sasaki M, Takeichi N, Kobayashi H, Dempo K and Mori M: New mutation causing hereditary hepatitis in the laboratory rat. J Hered 78: 361-365, 1987.

29. Li Y, Togashi Y, Sato S, Emoto T, Kang JH, Takeichi N, Kobayashi H, Kojima Y, Une Y and Uchino J: Spontaneous hepatic copper accumulation in Long-Evans Cinnamon rat with hereditary hepatitis. A model of Wilson's disease. J Clin Invest 87: 1858-1861, 1991.
30. Wu J, Forbes JR, Chen HS and Cox DW: The LEC rat has a deletion in the copper transporting ATPase gene homologous to the Wilson disease gene. Nat Genet 7: 541-545, 1994.

31. Masuda R, Yoshida MC, Sasaki M, Dempo K and Mori M: High susceptibility to hepatocellular carcinoma development in LEC rats with hereditary hepatitis. Jpn J Cancer Res 79: 828-835, 1988.

32. Marquez-Quinones A, Cipak A, Zarkovic K, Fattel-Fazenda S, Villa-Trevino S, Waeg G, Zarkovic N and Gueraud F: HNE-protein adducts formation in different pre-carcinogenic stages of hepatitis in LEC rats. Free Radic Res 44: 119-127, 2010.

33. Samuele A, Mangiagalli A, Armentero MT, Fancellu R, Bazzini E, Vairetti M, Ferrigno A, Richelmi P, Nappi G and Blandini F: Oxidative stress and pro-apoptotic conditions in a rodent model of Wilson's disease. Biochim Biophys Acta 1741: 325-330, 2005.

34. Madhani M, Barchowsky A, Klei L, Ross CR, Jackson SK, Swartz HM and James PE: Antibacterial peptide PR-39 affects local nitric oxide and preserves tissue oxygenation in the liver during septic shock. Biochim Biophys Acta 1588: 232-240, 2002.

35. Sato H, Shiiya A, Kimata M, Maebara K, Tamba M, Sakakura Y, Makino N, Sugiyama F, Yagami K, Moriguchi T, Takahashi S and Bannai S: Redox imbalance in cystine/glutamate transporterdeficient mice. J Biol Chem 280: 37423-37429, 2005.

36. Khan N, Williams BB, Hou H, Li H and Swartz HM: Repetitive tissue $\mathrm{pO}_{2}$ measurements by electron paramagnetic resonance oximetry: current status and future potential for experimental and clinical studies. Antioxid Redox Signal 9: 1169-1182, 2007.

37. Nagaoka Y, Iuchi, Y, Ikeda Y and Fujii J: Glutathione reductase is expressed at high levels in pancreatic islet cells. Redox Rep 9: 321-324, 2004

38. Fujii T, Fujii $\mathrm{J}$ and Taniguchi N: Augmented expression of peroxiredoxin VI in rat lung and kidney after birth implies an antioxidative role. Eur J Biochem 268: 218-225, 2001. 